REVIEW

\title{
Mutations in the hepatitis B virus polymerase gene associated with antiviral treatment for hepatitis B
}

\author{
M. Hussain and A. S. F. Lok Division of Gastroenterology, University of Michigan and Veterans Administration Medical Centers, Ann \\ Arbor, Michigan, USA
}

SUMMARY. Significant advances have been made, during the last 5 years, in the treatment of chronic hepatitis B. Several new antiviral agents: lamivudine, famciclovir, lobucavir and adefovir, have been shown to be safe and effective in inhibiting hepatitis B virus (HBV) replication. These compounds can be administered orally and are well tolerated. However, virus clearance is uncommon after short courses ( $<6$ months) of therapy. Lamivudine and famciclovir have been evaluated in Phase III clinical trials in patients with chronic

\section{INTRODUCTION}

The main aim of treatment for chronic hepatitis B is to suppress hepatitis B virus (HBV) replication before there is irreversible liver damage. Currently, interferon$\alpha$ (IFN- $\alpha$ ) is the only approved treatment for chronic hepatitis B. However, it has limited efficacy, is expensive and is associated with many unpleasant side-effects. In the last 5 years, several new antiviral agents have shown promise in the treatment of chronic hepatitis B, but long-term treatment is needed for sustained antiviral effects. Unfortunately, drug-resistant mutants have been found in some patients who have been on treatment for long durations (> 6 months). The incidence, clinical outcome and biological significance of these mutants will be reviewed.

\section{INTERFERON}

A 3-6 month course of IFN therapy induces a response: clearance of hepatitis B e antigen (HBeAg) and serum

Abbreviations: ALT, alanine aminotransferase; HBeAg, hepatitis B e antigen; HBsAg, hepatitis B surface antigen; HBV, hepatitis B virus; PCV-TP, penciclovir triphosphate.

Correspondence: Anna S. F. Lok, Division of Gastroenterology, University of Michigan Medical Center, 3912 Taubman Center, Box 0362, Ann Arbor, MI 48109, USA. hepatitis B as well as in liver transplant recipients. Unfortunately, drug-resistant mutants involving the HBV polymerase gene, leading to breakthrough infection, have been reported in some patients who have received long courses ( $\geq 12$ months) of treatment. The incidence, clinical outcome and biological significance of these mutants will be reviewed.

Keywords: adefovir, chronic hepatitis B, famciclovir, hepatitis B virus DNA, lamivudine.
HBV DNA, normalization of aminotransferase (ALT) levels and reduction of necroinflammatory activity in the liver in $\approx 30-40 \%$ of patients [1]. Long-term followup of responders showed that the antiviral response was sustained in most patients ( $>80 \%$ ), and clearance of hepatitis B surface antigen ( $\mathrm{HBsAg}$ ) was observed in $7-65 \%$ of the responders $[2,3]$. Several factors have been found to be associated with a favourable response to IFN therapy, the two most important being high ALT and low serum HBV DNA levels prior to treatment [3,4]. These two factors reflect endogenous immune clearance of infected hepatocytes. This explains why patients with perinatally acquired HBV infection, who are in the immune tolerant phase, have a very poor response to IFN therapy. A flare in ALT levels during IFN treatment has been reported to be associated with a favourable response to IFN therapy. These flares are thought to be related to IFN-induced immune lysis of infected hepatocytes. The importance of immune clearance - endogenous and IFN induced - in successful antiviral response to IFN therapy may be related to its role in the elimination of covalently-closed-circular (ccc) DNA (vide infra).

\section{ANTIVIRAL THER APY AND THE ROLE OF CCC DNA IN PERSISTENT HBV INFECTION}

In the last 5 years, many new antiviral agents have 
become available. Some of these antiviral agents have shown promise in clinical trials and may play a key role in the treatment of chronic hepatitis B [5]. The antiviral agents that have been extensively evaluated include: lamivudine, famciclovir, lobucavir and adefovir. They inhibit HBV replication by blocking reverse transcription of the (-) strand HBV DNA or synthesis of the (+) strand HBV DNA. Although these compounds induce a more rapid and marked decrease of serum HBV DNA levels than IFN, the rate of sustained antiviral response and HBeAg clearance after short courses (3-6 months) of therapy is very low. This may be related to the persistence of ccc DNA in hepatocyte nuclei. The ccc DNA serves as a template for transcription of pregenomic RNA and viral mRNA (Fig. 1) [6]. There are two sources of ccc DNA: entry of new virus particles into the hepatocyte; and translocation of newly synthesized HBV DNA from the hepatocyte cytoplasm via an intracellular conversion pathway [7]. Most antiviral agents that have been examined thus far have little or no effect on ccc DNA. This accounts for the rapid reappearance of serum HBV DNA after cessation of antiviral therapy. In theory, virus clearance can be achieved by long courses of potent antiviral agents, which completely inhibit synthesis of new HBV DNA and replenishment of ccc DNA, as long as the duration of treatment outlasts the existing pool of ccc DNA. However, the half-life of ccc DNA is very long and loss of ccc DNA appears to be dependent on loss of hepatocytes [8]. Based on viral kinetic studies in patients receiving lamivudine treatment, the half-life of infected hepatocytes has been estimated to be 10-100 days in one study [9] and more than 100 days in another study [10]. In patients with an infected hepatocyte half-life of 100 days, 1 year of treatment could reduce the number of infected cells to $\approx 8 \%$ of its initial value. Thus, virus clearance will require continuous treatment with a potent antiviral agent for longer than 1 year. The duration of treatment that is needed to deplete the existing pool of $\mathrm{ccc}$ DNA will be longer in patients with less active liver disease. Although prolonged or indefinite treatment may eventually lead to virus clearance, long-term treatment with antiviral agents has been shown to induce drug-resistant viral mutants. Thus, virus clearance will not be achievable in all patients, even with lifelong treatment.

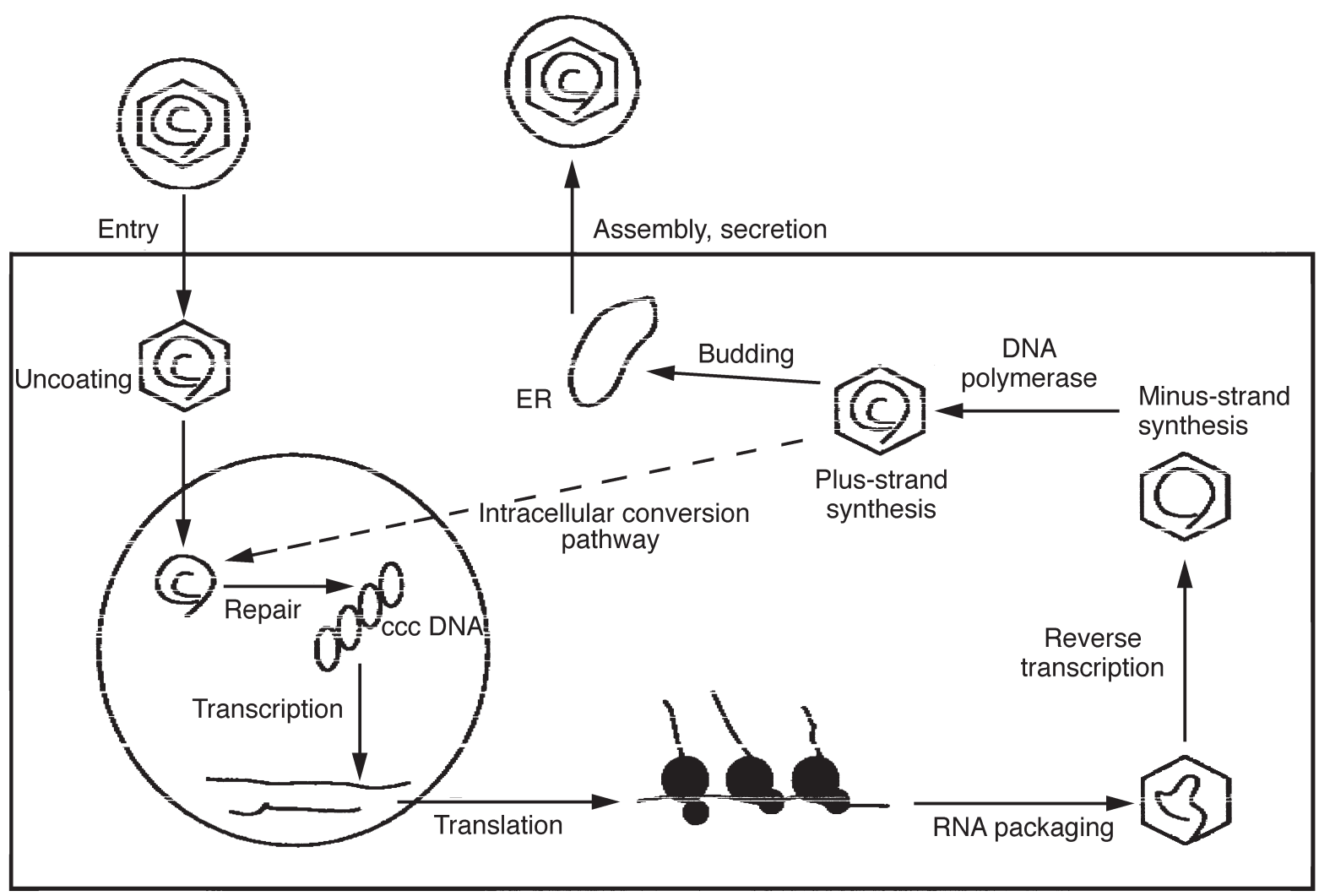

Fig. 1 Replication cycle of hepatitis B virus (HBV). 


\section{HBV POLYMERASE}

The HBV polymerase is a multifunctional protein with several distinct domains, including an N-terminal primer (for priming of reverse transcription), a spacer of indeterminate function, signals for viral pregenome encapsidation, RNA-dependent DNA synthesis, DNAdependent DNA synthesis, and RNase $\mathrm{H}$ activity (Fig. 2). Sequence alignment showed that the HBV polymerase shares homology with viral reverse transcriptases. The reverse transcriptase/DNA polymerase region can be divided into five domains: A, B, C, D and E (Fig. 2) [11]. Using sequence comparison and a knowledge of the crystal structure of the human immunodeficiency virus (HIV) reverse transcriptase, it is assumed that domains A, C and D of HBV polymerase are involved in nucleoside triphosphate binding and catalysis, while domains $\mathrm{B}$ and $\mathrm{E}$ may participate in the positioning of the RNA template and the primer, relative to the catalytic site [12-14]. The putative catalytic domain is believed to reside in the YMDD locus in domain C. This locus is conserved in all viral reverse transcriptases as well as in all isolates of hepadnaviruses [11]. Mutations involving substitution of methionine for valine or isoleucine $(\mathrm{M}-\mathrm{V} / \mathrm{I})$ have been reported in patients receiving lamivudine treatment for HIV or HBV infection. These mutations have been shown to decrease the sensitivity of HIV and $\mathrm{HBV}$ to lamivudine in in vitro studies and to result in breakthrough infection in clinical studies. Drug-resistant mutations have been found in association with every drug that has been used in the treatment of HIV infection. There are many similarities, as well as differences, between drug-resistant HIV and HBV mutants.

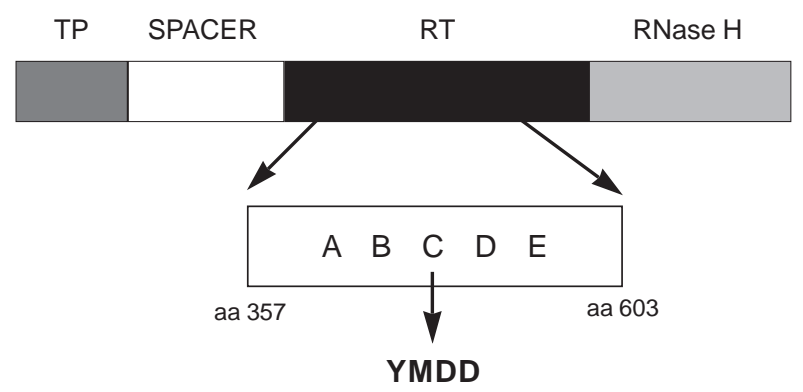

Fig. 2 Functional domains of the hepatitis B virus (HBV) polymerase. The reverse transcriptase/DNA polymerase domain has five conserved regions: A, B, C, D and E. TP, terminal protein; RT, reverse transcriptase.

\section{DRUG-RESISTANT HIV VARIANTS}

Drug-resistant HIV mutants are a major impediment to successful elimination of HIV [15]. Mutants tend to emerge early, within 3 months of onset of treatment, and are detected in the majority of treated patients. The high incidence of drug-resistant HIV mutants is related to the high rate of HIV replication and the infidelity of the HIV reverse transcriptase. In some instances, drug resistance is the result of a single amino acid substitution, but many HIV drugs induce a series of mutations with increasing resistance. Resistance to lamivudine is secondary to a single mutation involving the YMDD locus [16]. The initial mutation is usually a methionine to isoleucine substitution. The M184I mutation is subsequently replaced by a methionine to valine $(\mathrm{M} 184 \mathrm{~V})$ substitution. Using a limiting dilution approach, it was shown that the initial appearance of M184I is caused by mutational bias of the HIV reverse transcriptase [17]. In vitro studies, using an infected T-cell line, demonstrated that both M184I and M184V HIV variants have reduced replication fitness compared to the wild-type virus owing to a processivity defect of the reverse transcriptase enzyme, with the M184I variant being least fit and thus accounting for the subsequent outgrowth of the M184V variant [18]. High-level zidovudine resistance, however, requires multiple stepwise mutations, leading to a progressive decrease in response [19]. Mutations that are resistant to one drug may be cross-resistant to other drugs. As an example, the M184V mutation confers cross-resistance to lamivudine, (-)FTC, didanosine and zalcitabine [20]. Resistant mutants are rapidly selected when patients, who have prior exposure to one of these drugs, are treated with other drugs that are cross-resistant. However, resistance to one drug may also restore sensitivity to another drug. Thus, resistance to lamivudine caused by the M184V mutation has been shown to restore susceptibility to zidovudine in patients with pre-existing phenotypic zidovudine resistance [21]. The current approach to HIV treatment is combination therapy using drugs with additive/synergistic antiviral effects and different resistance profiles, in the hope of preventing or delaying resistance, and to switch to a different combination of drugs when resistance develops.

Another alternative is to search for new drugs that have a low rate of resistance. One of these is adefovir 
dipivoxil. In vitro studies found that exposure of HIVinfected cells to adefovir can select out two types of mutants: K65R and K70E. However, the K65R mutation has not been observed in vivo and the K70E mutation was detected in only two $(1.2 \%)$ of 171 patients who had received adefovir for 6-12 months [22]. In addition, preliminary data suggest that adefovir may be used as a 'rescue' therapy in patients with lamivudineresistant HIV mutants (M184I and M184V).

\section{LAMIVUDINE}

\section{Mechanisms of action}

Lamivudine (3TC) is the (-) enantiomer of 2'-deoxy-3'thiacytidine. It contains a sulphur atom in the 3 ' portion of the sugar ring. It is phosphorylated to the triphosphate (3TC-TP), which competes with dCTP for incorporation into growing DNA chains, causing chain termination [23]. This may occur during reverse transcription of the first strand as well as during synthesis of the second-strand HBV DNA, resulting in decreased synthesis of HBV DNA, export of new virions and intracellular replenishment of ccc DNA.

\section{Clinical efficacy}

Clinical trials have shown that short courses (4-24weeks) of orally administered lamivudine were well tolerated and produced a rapid and marked (>90\%) decrease in serum HBV DNA levels in patients with chronic hepatitis B. However, serum HBV DNA levels promptly reappeared after cessation of therapy, and very few (0-12\%) patients cleared HBeAg [24-26].

Several long-term clinical trials have been conducted. Preliminary results suggest that higher rates of sustained response (15-20\% HBeAg seroconversion) can be achieved with longer duration ( 1 year) of treatment. In one study, 358 Chinese patients with chronic hepatitis B were randomized to receive lamivudine, $100 \mathrm{mg}$ or $25 \mathrm{mg}$ daily, or placebo. The respective responses at the end of 1 year in the three groups were: HBeAg seroconversion in $16 \%, 13 \%$ and $4 \%$; and improvement in histological necroinflammatory score by $\geq 2$ in $56 \%, 49 \%$ and $25 \%$ [27]. Genotypic mutations in the YMDD locus were found in $4 \%$ and $14 \%$ (a mixture of wild-type and mutant $\mathrm{HBV}$ in $9 \%$ and mutant $\mathrm{HBV}$ alone in 5\%) of the treated patients at weeks 36 and 52, respectively.
The lack of myelotoxicity and the infrequent occurrence of serum ALT flares during lamivudine treatment led to clinical trials in patients with decompensated cirrhosis or recurrent hepatitis B after liver transplantation, conditions in which IFN is ineffective and potentially hazardous. Preliminary results suggest that lamivudine is safe and effective in inhibiting HBV replication and in improving liver disease in these patients. Two studies reported that lamivudine, initiated prior to liver transplantation and continuing post-transplant in the absence of hepatitis B immune globulin (HBIg), was effective in preventing HBV reinfection post-transplant $[28,29]$. In one study, lamivudine monotherapy prevented HBV reinfection in $80 \%$ of patients transplanted for hepatitis B but five (three pre- and two post-transplant) patients developed breakthrough infection owing to lamivudine-resistant mutants. Lamivudine is also used in the treatment of recurrent hepatitis B post-transplant. In one North American study, 63 patients received lamivudine for recurrent hepatitis B postliver transplant [30]. Serum HBV DNA was detectable by hybridization assay in $87 \%$ of patients prior to treatment but in only $4 \%$ and $25 \%$ of patients after 24 and 52 weeks of treatment, respectively. Breakthrough infection, secondary to development of lamivudine-resistant mutants, developed in $14(27 \%)$ patients who received at least 6 months of treatment.

\section{Lamivudine-resistant mutants}

Lamivudine-resistant mutants leading to breakthrough infection (persistent reappearance of $\mathrm{HBV}$ DNA in serum that is preceded by at least two consecutive negative serum HBV DNA test results using nonpolymerase chain reaction (PCR)-based assays) have been detected in $\approx 15-25 \%$ of immunocompetent patients with chronic hepatitis $\mathrm{B}$ and in $\approx 25 \%$ of transplant recipients, after 1 year of lamivudine therapy $[27,30,31]$. One study found that lamivudineresistant mutants could also be found in some patients with incomplete response [32]. Lamivudine-resistant mutants have not been detected in untreated patients or in patients who have received short courses (<6 months) of therapy [27,32]. Most studies reported that resistant mutants were first detected after 8-9 months of treatment and may precede phenotypic resistance by $1-4$ months $[27,33]$. The incidence of resistant mutations increases with the duration of 
treatment. Preliminary data in an Asian study found that the rate of genotypic resistance increased from $14 \%$ after 1 year to $38 \%$ after 2 years of lamivudine (100 mg daily) while the rate of $\mathrm{HBeAg}$ seroconversion increased from 16 to $27 \%$ only [34]. Thus, the benefit vs risk of indefinite treatment must be carefully weighed.

A variety of $\mathrm{HBV} P$-gene mutations have been described in patients on lamivudine therapy (Table 1) (Fig. 3) $[27,28,32,33,35-45]$. So far, only three mutations have been clearly shown to confer resistance to lamivudine treatment $[35,38,46]$. These include methionine to valine or isoleucine (M552V or M552I) substitutions involving the YMDD locus in domain $\mathrm{C}$ and leucine to methionine substitution at codon 528 (L528M) in domain B. The L528M mutation has not been observed in lamivudine-resistant HIV mutants because there is no equivalent site in the HIV reverse transcriptase. The L528M mutation is almost always found in association with the M552V mutation but rare cases of association with M552I have been reported [41, personal observations]. Isolated occurrence of L528M has not been observed. Both mutations involving the YMDD locus result in amino acid substitutions (codons 195 and 196) in the overlapping HBV $S$-gene. Because these residues are located outside the 'a' determinant of the surface protein, it is unlikely that these changes would affect the immune response to HBsAg. The L528M mutation has no effect on the amino acid sequence of the $S$-gene. Another mutation, $\mathrm{V} 521 \mathrm{~L}$, involving domain $\mathrm{B}$, has been reported in a few patients with lamivudine resistance [35,37,38]. Because V521L was always present in association with $\mathrm{L} 528 \mathrm{M}$ and $\mathrm{M} 552 \mathrm{~V}$, the effect of the isolated V521L mutation on lamivudine sensitivity is not clear. The V521L mutation results in an amino acid substitution at codon 164 of the overlapping $S$-gene. It is possible that the V521L mutation may have an impact on the humoral response to HBsAg as it is located very close to the ' $a$ ' determinant and the residues that define the $w / r$ subtype of HBsAg.

In vitro studies using a transient transfection cell culture assay demonstrated that each of the three common lamivudine-resistant mutations significantly decreased the sensitivity of $\mathrm{HBV}$ to lamivudine treatment. Mutants with M552I, L528M + M552V or $\mathrm{L} 528 \mathrm{M}+\mathrm{M} 552 \mathrm{I}$ increased the $\mathrm{IC}_{50}$ by $>10000$-fold, while mutants with M552V or L528M induced less resistance, with an increase in $\mathrm{IC}_{50}$ of 153- and 18- fold, respectively [35]. Because M552I and L528M + M552V mutants are the most common mutants found in patients with breakthrough infection, clinical response cannot be restored with dose escalation. The mechanism by which these mutations confer resistance to lamivudine is not clear. Allen et al. constructed a three-dimensional homology model of the HBV reverse transcriptase (RT) based on the HIV RT crystal structure $[14,35,47]$. This model has thumb, palm and finger domains. Lamivudine binds at a pocket in the surface of the enzyme (palm region) formed, in part, by residue 552. As the side-chain gets smaller $(\mathrm{M}-\mathrm{V} / \mathrm{I})$, the size of the binding pocket increases and the affinity of lamivudine for the pocket decreases, leading to loss of efficacy. L528 is spatially very close to M552, thus mutation involving L528 may affect the pocket that binds lamivudine.

Currently, it is not clear which of the two YMDD mutations is more common and why some patients develop M552V while others develop M552I. One study reported that $18(90 \%)$ of 20 patients with breakthrough infection whilst on lamivudine had $\mathrm{L} 528 \mathrm{M}+\mathrm{M} 552 \mathrm{~V}$, suggesting that the M552V mutant is predominant [35]. However, other studies reported that M552I was more common [32,33]. Further studies involving consecutive patients in clinical trials are needed to resolve the issue of relative preponderance of the two YMDD mutations. Unlike patients with HIV infection, a switch from M552I to M552V has not been reported.

Emergence of lamivudine-resistant mutants is usually accompanied by the reappearance of serum HBV DNA after its initial clearance. However, the clinical manifestations are variable. In most patients, serum HBV DNA and ALT levels remain lower than pretreatment values, suggesting that the mutants may have little clinical consequence [27]. However, flares in hepatitis and hepatic decompensation have been reported in a small percentage of patients who have breakthrough infection $[39,48]$. The incidence of significant flares, and risk factors for their occurrence in patients with breakthrough infection, are unknown. It is also not clear if patients who have asymptomatic, mildly elevated ALT levels after breakthrough infection will remain clinically stable during long-term followup. Thus, the benefits of treatment must be weighed against the risks of developing drug-resistant mutants and the uncertain long-term outcome of patients with breakthrough infection. 
188 M. Hussain \& A. S. F. Lo

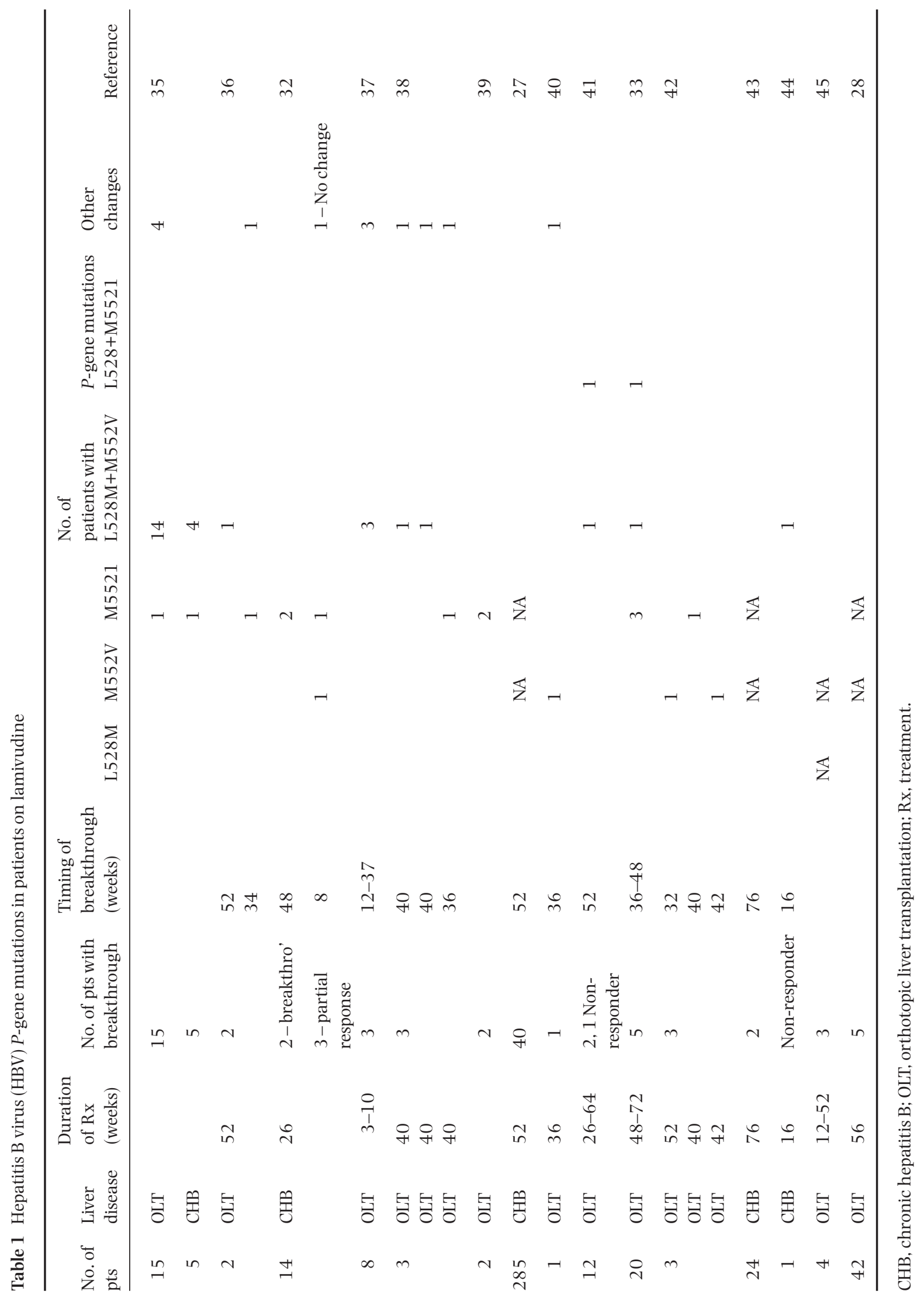

(C) 1999 Blackwell Science Ltd, Journal of Viral Hepatitis, 6, 183-194 


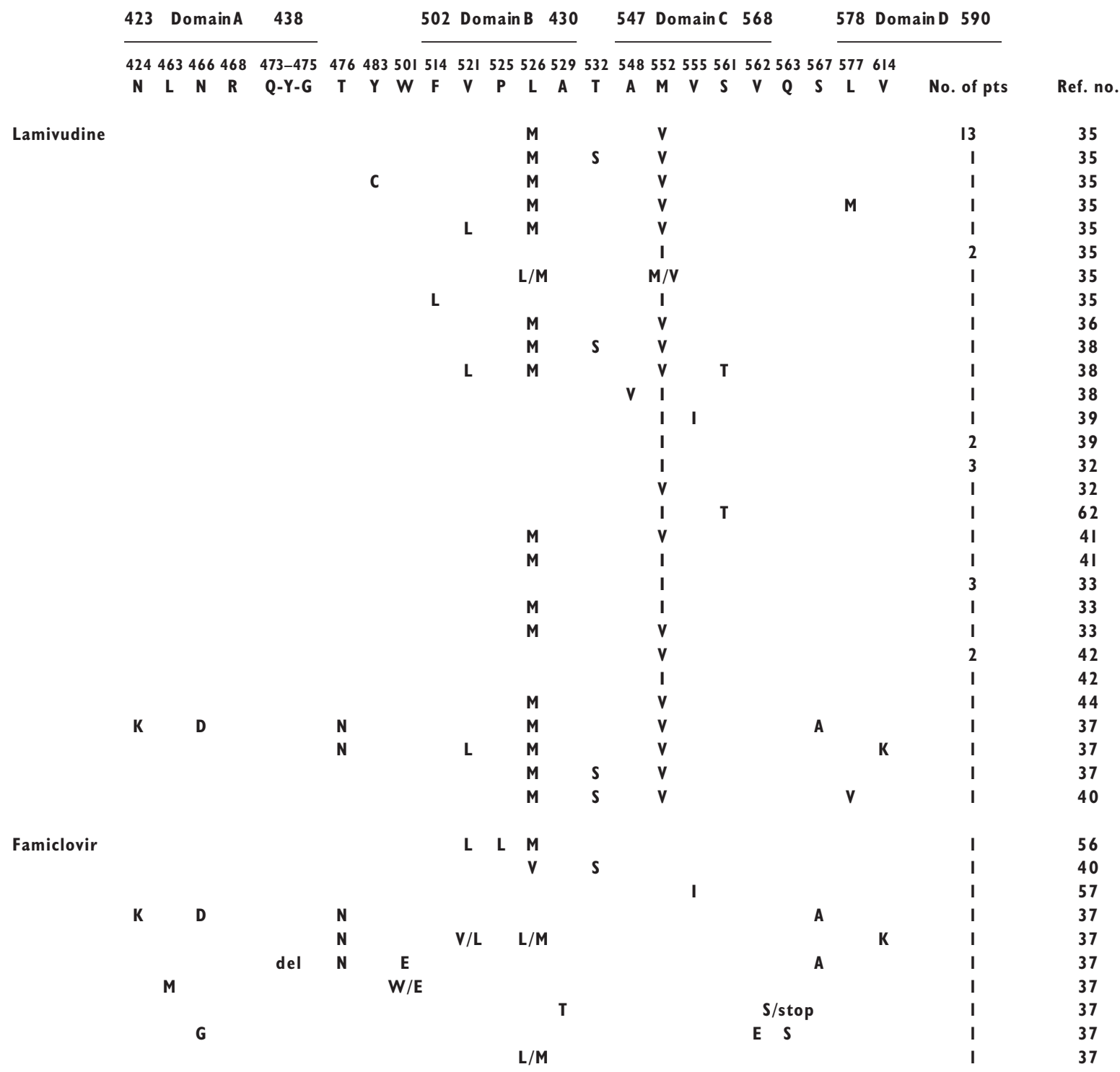

Fig. 3 Frequency and location of hepatitis B virus (HBV) P-gene mutations in patients who received famciclovir or lamivudine therapy.

The low serum HBV DNA levels in the majority of patients with breakthrough infection is probably related to the decreased replication capacity of the mutants compared to wild-type virus. In vitro studies using transiently transfected cell cultures demonstrated that the mutants M552I, M552V, and the combination of either of these mutants with L528M, have significantly decreased replication capacity whilst the L528M mutation alone has no impact on HBV replication [49]. Another mutation, F514L, involving domain $\mathrm{B}$, was found to have the greatest impact on $\mathrm{HBV}$ replication but this mutation has only been reported in one patient so far [36], thus its clinical significance is unknown. None of these mutations, except for F514L, affect HBV RNA transcription or HBsAg secretion. The diminished replication capacity of the mutants accounts for the rapid outgrowth of the wild-type virus upon cessation of treatment [33]. Flares in hepatitis owing to the re-emergence of wild-type virus have been reported in patients after withdrawal of lamivudine therapy. Thus, current recommendations are to maintain patients with breakthrough infection on lamivudine treatment to suppress residual wild-type virus. 


\section{FAMCICLOVIR}

\section{Mechanisms of action}

Famciclovir is the oral prodrug of penciclovir, an acyclic deoxyguanosine analogue. Penciclovir is phosphorylated to its triphosphate (PCV-TP), which competes with dGTP for incorporation into the nascent $\mathrm{HBV}$ DNA chains. Incorporation of PCV-TP into nascent HBV DNA may lead to premature chain termination or destabilization of the HBV DNA chains [50]. In addition, PCV-TP may compete with dGTP for the priming of reverse transcription (synthesis of the first HBV DNA strand) [51].

\section{Clinical efficacy}

Pilot studies and preliminary reports of ongoing clinical studies found that famciclovir is well tolerated and can inhibit HBV replication [52,53]. Available data suggest that famciclovir induces a slower and less marked decrease in serum HBV DNA levels compared with lamivudine, but data on the rate of HBeAg seroconversion and the effect on liver histology in patients who have received 1 year of famciclovir treatment are not yet available. Famciclovir has also been shown to be effective in reducing HBV replication and in improving liver disease in patients with decompensated cirrhosis or recurrent hepatitis B after liver transplantation, but data are limited and the rate of sustained response is not known [54,55].

\section{Famciclovir-resistant mutants}

Drug-resistant mutants have also been reported in patients who have been on long-term famciclovir treatment (Table 2) (Fig. 3) [37,40,56,57]. Reports on famciclovir-resistant mutants have been scanty. It is not clear if the scarcity of reports is related to a lower incidence of famciclovir-resistant mutation, a smaller number of patients who have received famciclovir for long durations (> 12 months), or under-reporting. Thus, the exact incidence, location and clinical significance of famciclovir-resistant mutants have not been defined. Preliminary data suggest that the YMDD locus is not involved. Most famciclovir-associated mutations are found in domain B of the HBV P-gene. The most common mutation is L528M, which is also found in patients with lamivudine resistance. In some patients, the L528M mutation is present in association with mutations in other regions of the HBV P-gene but no consistent pattern can be discerned. Not all famciclovir-associated mutations have been clearly linked to drug resistance because some of the mutations were found in non-responders. The two most common famciclovir-associated mutations, L528M and V521L, have been demonstrated to induce famciclovir resistance. The L528M mutation, with or without the V521L mutation, was found in patients with breakthrough infection. In addition, serum samples with both mutants were found to be resistant to PCV-TP in an endogenous polymerase assay [56]. As in patients with lamivudine resistance, the V521L mutation always occurred in association with L528M. The effect of the isolated V521L mutation on famciclovir sensitivity is therefore unclear. Another mutation, V555I, involving domain $\mathrm{C}$, has been detected in a patient who had breakthrough infection whilst on famciclovir treatment [57]. The V551I mutation causes premature termination of the overlapping envelope protein. The detrimental effect on the envelope protein may explain why this mutant has only been reported in one patient.

The finding of $\mathrm{L} 528 \mathrm{M} \pm \mathrm{V} 521 \mathrm{~L}$ mutations in patients with lamivudine, as well as famciclovir resistance, suggests that patients who develop these

Table 2 Clinical data and frequency of HBV P gene mutations in patients undergoing famciclovir therapy

\begin{tabular}{|c|c|c|c|c|c|c|}
\hline Reference & $\begin{array}{l}\text { Number of } \\
\text { patients }\end{array}$ & $\begin{array}{l}\text { Liver } \\
\text { disease }\end{array}$ & $\begin{array}{l}\text { Duration of } \mathrm{Rx} \\
\text { (weeks) }\end{array}$ & $\begin{array}{l}\text { Number of } \\
\text { patients with } \\
\text { breakthrough }\end{array}$ & $\begin{array}{l}\text { Timing of } \\
\text { breakthrough } \\
\text { (weeks) }\end{array}$ & P gene mutations \\
\hline 56 & 1 & OLT & 52 & 1 & NA & V521L, P525L, L528M \\
\hline 57 & 15 & $\mathrm{CHB}$ & 16 & 4 & & V5551 (1) \\
\hline 60 & 5 & NA & & $\begin{array}{l}3 \\
2 \text { Non-responders }\end{array}$ & $24-72$ & $\begin{array}{l}\text { B domain } \\
\text { Upstream of B domain }\end{array}$ \\
\hline 37 & 8 & OLT & $41-113$ & 8 & & See Fig. 3 \\
\hline
\end{tabular}


mutations whilst receiving famciclovir will also be resistant to lamivudine, and vice versa. Preliminary data showed that patients who developed breakthrough infection during famciclovir therapy because of the L528M mutation initially responded when switched to lamivudine treatment but breakthrough infection occurred within 6 months of lamivudine therapy owing to rapid selection of the M552V mutation [37].

\section{OTHER NEW ANTIVIRAL AGENTS}

Several other new antiviral agents have been shown to be effective in inhibiting $\mathrm{HBV}$ replication in in vitro as well as in Phase I and II clinical studies. These include lobucavir, BMS-200475, FTC, L-FMAU and adefovir. Of these, lobucavir and adefovir have been the most thoroughly studied. Lobucavir is a guanine nucleoside analogue synthesized from 2'-deoxyguanosine, with replacement of the sugar by a cyclobutyl ring. Lobucavir triphosphate is a potent inhibitor of the HBV DNA polymerase. It acts mainly as a chain terminator. Adefovir dipivoxil is an oral prodrug of adefovir (PMEA), a phosphonate nucleotide analogue of adenosine monophosphate. Adefovir is phosphorylated to the diphosphate, which competes with dATP for incorporation into growing DNA chains, causing chain termination. Phase II clinical trials involving a 3-month course of treatment showed that both lobucavir and adefovir dipivoxil were well tolerated. Serum HBV DNA levels decreased by $3-4 \operatorname{logs}$, and a small (10-20\%) percentage of patients developed HBeAg seroconversion [58,59]. So far, resistant HBV mutants have not been reported in association with any of these new antiviral agents because of the short duration of treatment. Whether these new drugs can induce resistant mutants, the frequency with which they will occur, and the clinical significance of these mutants, will be determined in Phase III clinical trials when treatment will be administered for a minimum of 1 year.

\section{PREVENTION OR TREATMENT OF DRUG- RESISTANT HBV P-GENE MUTANTS}

Ideally, it is preferable to prevent drug-resistant mutants because of the potential adverse clinical outcome in patients who develop breakthrough infection and the lack of 'rescue' therapy of proven efficacy. The approach in the treatment of HIV infection is to use a combination of antiviral agents that have additive or synergistic antiviral effects and different resistance profiles. This approach has the potential advantage that early, aggressive treatment may have a better chance of inducing virus clearance and preventing resistant mutations and the disadvantages of added costs and toxicity. Initiation of treatment using a combination of antiviral agents has not been explored in the treatment of chronic HBV infection because of the limited number of drugs available and the lack of data on the long-term safety, efficacy and resistance profile of each drug. Some investigators have argued that this approach may not be necessary given the slow and infrequent emergence of drug-resistant mutants in patients with $\mathrm{HBV}$ infection (compared with HIV infection) and the 'benign' outcome of patients with breakthrough infection. A more logical approach in the treatment of HBV infection may be monotherapy, initially, followed by a switch to alternative antiviral agents or to add on other antiviral agents in patients with breakthrough infection. However, sequential therapy is feasible only if alternative agents that are not cross-resistant or are effective as 'rescue' therapy are available. Among the new antiviral agents that have proven efficacy in Phase II or III clinical trials for chronic hepatitis B, famciclovir and lamivudine have been shown to have additive or synergistic antiviral effects in in vitro studies [60] but both drugs share overlapping resistance profiles. Pilot studies found that lamivudine cannot be used as 'rescue' therapy for patients with famciclovir resistance and vice versa $[37,61]$. Whether combination of the two drugs ab initio can have an additive or synergistic antiviral effect or the ability to delay the emergence of resistant mutants in vivo remains to be determined. In vitro studies found that the inhibition constants of adefovir for lamivudine-resistant HBV mutant vs wild-type HBV DNA polymerases were increased by twofold only while the inhibition constants of lamivudine were increased by 2-25-fold [62]. Whether adefovir is effective as a 'rescue' therapy in patients with breakthrough infection caused by lamivudine-resistant HBV mutants remains to be proven.

\section{REFERENCES}

1 Wong DK, Cheung AM, O'Rourke K, Naylor CD, Detsky AS, Heathcote J. Effect of alpha-interferon treatment in patients with hepatitis B e antigen-positive chronic hepatitis B. A meta analysis. Ann Intern Med 1993; 119: 312-323. 
2 Korenman J, Baker B, Waggoner J, Everhart JE, Di Bisceglie AM, Hoofnagle JH. Long-term remission of chronic hepatitis B after alpha-interferon therapy. Ann Intern Med 1991; 114: 629-634.

3 Lok AS, Chung HT, Liu VW, Ma OC. Long-term follow-up of chronic hepatitis B patients treated with interferon alfa. Gastroenterology 1993; 105: 1833-1838.

4 Brook MG, Karayannis P, Thomas HC. Which patients with chronic hepatitis $\mathrm{B}$ virus infection will respond to alpha interferon therapy? A statistical analysis of predictive factors. Hepatology 1989; 10: 761-766.

5 Zoulim F, Trepo C. Drug therapy for chronic hepatitis B: antiviral efficacy and influence of hepatitis B virus polymerase mutations on the outcome of therapy. J Hepatol 1998; 29: 151-168.

6 Ganem D. Hepadnaviridae and their replication. In: Feilds Virology, 3rd edn. 1996: 2703-2737.

7 Lenhoff RJ, Summers J. Coordinate regulation of replication and virus assembly by the large envelope protein of an avian hepadnavirus. J Virol 1994; 68: 4565-4571.

8 Moraleda G, Saputelli J, Aldrich CE, Averett D, Condreay L, Mason WM. Lack of effect of antiviral therapy in nondividing hepatocyte cultures on the closed circular DNA of woodchuck hepatitis virus. J Virol 1997; 71: 9392-9399.

9 Nowak MA, Bonhoeffer S, Hill AM, Boehme R, Thomas $\mathrm{HC}$, McDade H. Viral dynamics in hepatitis B virus infection. Proc Natl Acad Sci USA 1996; 93: 4398-4402.

10 Zeuzem S, de Man RA, Honkoop P, Roth WK, Schalm SW, Schmidt JM. Dynamics of hepatitis B virus infection in vivo. J Hepatol 1997; 27: 431-436.

11 Poch O, Sauvaget I, Delarue M, Tordo N. Identification of four conserved motifs among the RNA-dependent polymerase encoding elements. EMBO J 1989; 8: 3867-3874.

12 Li MD, Bronson DL, Lemke TD, Faras AJ. Phylogenetic analyses of 55 retroelements on the basis of the nucleotide and product amino acid sequences of the pol gene. Mol Biol Evol 1995; 12: 657-670.

13 Johnson MS, McClure MA, Feng DF, Gray J, Doolittle RF. Computer analysis of retroviral pol genes: assignment of enzymatic functions to specific sequences and homologies with nonviral enzymes. Proc Natl Acad Sci USA 1986; 83: 7648-7652.

14 Kohlstaedt LA, Wang J, Friedman JM, Rice PA, Steitz TA. Crystal structure at 3.5 A resolution of HIV-1 reverse transcriptase complexed with an inhibitor. Science 1992; 256: 1783-1790.

15 Kuritzkes DR. Clinical significance of drug resistance in HIV-1 infection. AIDS 1996; 10: S27-S31.

16 Boucher CA, Cammack N, Schipper P et al. High-level resistance to (-) enantiomeric 2'-deoxy-3'-thiacytidine in vitro is due to one amino acid substitution in the catalytic site of human immunodeficiency virus type 1 reverse transcriptase. Antimicrob Agents Chemother 1993; 37 : 2231-2234

17 Keulen W, Back NK, van Wijk A, Boucher CA, Berkhout B. Initial appearance of the 184Ile variant in lamivudinetreated patients is caused by the mutational bias of human immunodeficiency virus type 1 reverse transcriptase. J Virol 1997; 71: 3346-3350.

18 Back NK, Nijhuis M, Keulen W et al. Reduced replication of 3TC-resistant HIV-1 variants in primary cells due to a processivity defect of the reverse transcriptase enzyme. ЕМВО J 1996; 15: 4040-4049.

19 Larder BA, Kemp SD. Multiple mutations in HIV-1 reverse transcriptase confer high-level resistance to zidovudine (AZT). Science 1989; 246: 1155-1158.

20 Gao Q, Gu Z, Parniak MA et al. The same mutation that encodes low-level human immunodeficiency virus type 1 resistance to 2',3'- dideoxyinosine and 2',3'-dideoxycytidine confers high-level resistance to the (-) enantiomer of 2',3'-dideoxy-3'-thiacytidine. Antimicrob Agents Chemother 1993; 37: 1390-1392.

21 Larder BA, Kemp SD, Harrigan PR. Potential mechanism for sustained antiretroviral efficacy of AZT-3TC combination therapy. Science 1995; 269: 696-699.

22 Mulato AS, Lamy PD, Miller MD et al. Genotypic and phenotypic characterization of human immunodeficiency virus type 1 variants isolated from AIDS patients after prolonged adefovir dipivoxil therapy. Antimicrob Agents Chemother 1998; 42: 1620-1628.

23 Severini A, Liu XY, Wilson JS, Tyrrell DLJ. Mechanism of inhibition of duck hepatitis B virus polymerase by (-) -BL-2,3-dideoxy-3-thiacytidine. Antimicrob Agents Chemother 1995; 39: 1430-1435.

24 Lai CL, Ching CK, Tung AKM et al. Lamivudine is effective in suppressing hepatitis B virus DNA in Chinese hepatitis B surface antigen carriers: a placebo controlled trial. Hepatology 1997; 25: 241-244.

25 Dienstag JL, Perrillo R, Schiff E, Bartholomew M, Vicary C, Rubin M. A preliminary trial of lamivudine for chronic hepatitis B infection. $N$ Engl J Med 1995; 333: 1657-1661.

26 Nevens F, Main J, Honkoop P et al. Lamivudine therapy for chronic hepatitis B. A six-month randomized dose ranging study. Gastroenterology 1997; 113: 1258-1263.

27 Lai CL, Chien RN, Leung NWY et al. A one year trial of lamivudine for chronic hepatitis B. N Engl J Med 1998; 339: 61-68.

28 Perrillo R, Rakela J, Martin P et al. Lamivudine for suppression and/or prevention of hepatitis B when given pre/post-liver transplantation (OLT). Hepatology 1997; 26: A526.

29 Grellier L, Mutimer D, Ahmed M et al. Lamivudine prophylaxis against reinfection in liver transplantation for hepatitis B cirrhosis. Lancet 1996; 348: 1212-1215.

30 Perrillo R, Rakela J, Martin P et al. Long term lamivudine therapy of patients with recurrent hepatitis $B$ 
post-liver transplantation. Hepatology 1997; 26: A196.

31 Dienstag JL, Schiff ER, Mitchell M et al. Extended lamivudine retreatment for chronic hepatitis B. Hepatology 1996; 24: A188.

32 Honkoop P, Niesters HGM, deMan RAM, Osterhaus ADME, Schalm SW. Lamivudine resistance in immunocompetent chronic hepatitis B. Incidence and patterns. J Hepatol 1997; 26: 1393-1395.

33 Chayama K, Suzuki Y, Kobayashi M et al. Emergence and takeover of YMDD motif mutant hepatitis B virus during long therapy and re-takeover by wild type after cessation of therapy. Hepatology 1998; 27: 1711-1716.

34 Liaw YF, Lai CL, Leung NWY et al. Two-year lamivudine therapy in chronic hepatitis B infection: results of a placebo controlled multicentre study in Asia. Gastroenterology 1998; 114: A1289.

35 Allen MI, Deslauriers M, Andrews CW et al. Identification and characterization of mutations in hepatitis B virus resistant to lamivudine. Hepatology 1998; 27: 1670-1677.

36 Ling R, Mutimer D, Ahmed M et al. Selection of mutations in the hepatitis $\mathrm{B}$ virus polymerase during therapy of transplant recipients with lamivudine. Hepatology 1996; 24: 711-713.

37 Tillmann HL, Trautwein C, Bock T et al. Response and mutations in patients sequentially treated with lamivudine and famciclovir for recurrent hepatitis B after liver transplantation. Hepatology 1997; 26: A1202.

38 Bartholomew MM, Jansen RW, Jeffers LJ et al. Hepatitis-Bvirus resistance to lamivudine given for recurrent infection after orthotopic liver transplantation. Lancet 1997; 349: 20-22.

39 Tipples GA, Ma MM, Fischer KP, Bain VG, Kneteman NM, Tyrrell DL. Mutation in HBV RNA-dependant DNA polymerase confers resistance to lamivudine in vivo. Hepatology 1996; 24: 714-717.

40 Naoumov NV, Chokshi S, Smith H, Williams R. Emergence and characterisation of lamivudine resistant hepatitis B virus variant. Hepatology 1996; 24: A282.

41 Petit MA, Buffello D, Roche B et al. Residual hepatitis B virus (HBV) infection in liver transplant patients under treatment with lamivudine (3TC): assessment by quantitation of HBV DNA by PCR and assay of preS antigens. Hepatology 1997; 26: A746.

42 Shields PL, Ling R, Harrison T, Boxall E, Elias E, Mutimer DJ. Management and outcome of lamivudine (LAM)resistant hepatitis B virus (HBV) infection after liver transplantation (LT). Hepatology 1997; 26: A527.

43 Garrett L, Dienstag JL, Gauthier J et al. Hepatitis B e antigen $(\mathrm{HBe} A g)$ seroconversion in two patients with evidence of genotypic resistance following extended lamivudine treatment. Hepatology 1997; 26: A1209.
44 Buti M, Jardi R, Cotrina M, Rodriguez-Frias F, Esteban R, Guardia J. Hepatitis flare in a patient with chronic hepatitis B non-responder to lamivudine: emergence of hepatitis B variants. Hepatology 1997; 26: A1436.

45 Rodriguez MJ, Martinez EJ, Magill A et al. Clinical management of hepatitis B recurrence after liver transplantation with lamivudine resistant strains. Hepatology 1997; 26: A1847.

46 Fischer KP, Tyrrell DLJ. Generation of duck hepatitis B virus polymerase mutants through site-directed mutagenesis which demonstrate resistance to lamivudine [(-)-BL-2,3-Dideoxy-3-Thiacytidine] in vitro. Antimicrob Agents Chemother 1996; 40: 1957-1960.

47 Jacobo-Molina A, Ding J, Nanni RG et al. Crystal structure of human immunodeficiency virus type 1 reverse transcriptase complexed with double-stranded DNA at $3.0 \mathrm{~A}$ resolution shows bent DNA. Proc Natl Acad Sci USA 1993; 90: 6320-6324.

48 Honkoop P, De Man RA, Heijtink RA, Schalm SW. Hepatitis B reactivation after lamivudine. Lancet 1995; 346: 1156-1157.

49 Melegari M, Scaglioni PP, Wands JR. Hepatitis B virus mutants associated with $3 \mathrm{TC}$ and famciclovir administration are replication defective. Hepatology 1998; 27 : 628-633.

50 Shaw T, Mok SS, Locarnini SS. Inhibition of hepatitis B virus DNA polymerase by enantiomers of penciclovir triphosphate and metabolic basis for selective inhibition of HBV replication by penciclovir. Hepatology 1996; 24: 996-1002.

51 Zoulim F, Dannaoui E, Trepo C. Inhibitory effect of penciclovir on the priming of hepadnavirus reverse transcription. Abstract from the 35th International Conference on Antimicrobial Agents and Chemotherapy 1995; A182.

52 Main J, Brown JL, Howells C et al. A double blind, placebocontrolled study to assess the effect of famciclovir on virus replication in patients with chronic hepatitis B virus infection. J Viral Hep 1996; 3: 211-215.

53 Trepo C, Jezek P, Atkinson G, Boon R. Efficacy of famciclovir in chronic hepatitis B: results of a dose finding study. Hepatology 1996; 24: A188.

54 Neuhaus P, Manns M, Atkinson G. Safety and efficacy of famciclovir for the treatment of recurrent hepatitis B in liver transplant recipients. Hepatology 1997; 26: A528.

55 Kruger M, Tillmann HL, Trautwein C et al. Famciclovir treatment of hepatitis B virus recurrence after liver transplantation: a pilot study. Liver Transpl Surg 1996; 2: 253-262.

56 Aye TT, Bartholomeusz AI, Shaw T et al. Hepatitis B virus polymerase mutations during antiviral therapy in a patient following liver transplantation. J Hepatol 1997; 26: 1148-1153.

57 Zoulim F, Pichoud C, Wang Z, Aguesse-Germonb S, Trepo C. Hepatitis B virus genome variability during famciclovir therapy. Hepatology 1997; 26: A1200. 
58 Heathcote EJ, Jeffers L, Wright T et al. Loss of serum HBV DNA and HBeAg and seroconversion following shortterm (12 weeks) adefovir dipivoxil therapy in chronic hepatitis B: two placebo-controlled phase II studies. Hepatology 1998; 28: A620.

59 Heathcote J, Chan R, McHutchison J et al. A phase II multicenter study of oral lobucavir for treatment of chronic hepatitis B. Hepatology 1998; 28: A621.

60 Colledge D, Locarnini S, Shaw T. Synergistic inhibition of hepadnaviral replication by lamivudine in combination with penciclovir in vitro. Hepatology 1997; 26:
$216-225$.

61 Locarnini SA, Aye TT, Shaw T et al. The emergence of famciclovir resistant mutations in the hepatitis $\mathrm{B}$ virus polymerase during therapy in patients following liver transplantation. Hepatology 1997; 26: A958.

62 De Man RA, Bartholomeusz A, Locarnini S, Niesters HGM, Zondervan PE. The occurrence of sequential viral mutations in a liver transplant recipient re-infected with hepatitis B: primary famciclovir resistance followed by a lethal hepatitis during acquired lamivudine resistance. J Hepatol 1997; 26 : 77. 